\title{
Prevalência de cárie dentária na comunidade ribeirinha São José - Vila Arara, AM
}

\section{Prevalence of dental care in the community riverside São José - Vila Arara, AM}

DOI: $10.46919 / \operatorname{archv2n6-002~}$

Recebimento dos originais: 01/06/2021

Aceitação para publicação: 31/07/2021

\section{Reuber Mendes Rocha}

Cirurgião-dentista: Mestrando em Ciências Aplicadas a Produtos para Saúde - Universidade Estadual de Goiás. End: Br 153 Quadra Área Km 99 Zona Rural, Anápolis - GO, 75132-903

\section{Andressa Ribeiro Araújo}

Cirurgiã-dentista: Especialista em Endodontia - Iniciativa Privada. End: Rua Rio Claro Q.06 Lt. 06 apt 1 - Vila Eduarda, São Luís de Montes Belos, 76100-000

\section{Ighor Fernandes Prado}

Cirurgião-dentista: Especialista em Endodontia - Iniciativa Privada. End: Rua 15 de dezembro, 157, Sala 2, 2 andar, Centro, Anápolis, Goiás, 75024-070

\section{Vanessa Hayanne Ramos dos Santos}

Cirurgiã-dentista - Iniciativa Privada. End: Av. Universitária Km. 3,5 - Cidade Universitária - Anápolis - Goiás: 75083-515

\section{Julianna Amaral Cavalcante}

Doutoranda em Ciências da Saúde, pela Faculdade de Medicina da Universidade Federal de Goiás, mestre em clínica odontológica pela UFG, especialista em odontopediatria, docente da Associação Brasileira de

Odontologia - Goiás regional Anápolis, coordenadora do curso de Odontologia da Faculdade Anhanguera - unidade Anápolis. End: End: Rua Celso Máximo Pereira Q. 48 Lt. 19, São Carlos, Anápolis - Goiás, 75084-110

\section{RESUMO}

No Brasil, dados so SB Brasilrevelam maiores níveis de cárie na região Norte e menores nas regiões Sudeste e Sul. As populações ribeirinhas próximas à bacia hidrográfica amazônica possuem alta prevalência de cárie dentária aliada à dificuldade de acesso aos serviços de saúde, limitando ao acesso à prevenção e promoção e reabilitação em saúde bucal.. O objetivo desse estudo transversal quantitativo foi identificar o perfil epidemiológico da cárie dentária em moradores da comunidade ribeirinha São José - Vila Arara Município de Caapiranga - Amazonas (AM). Para avaliação da condição dentária, após aprovação do Comitê de Ética e Pesquisa do Centro Universitário de Anápolis - UniEVANGÉLICA (parecer 1.053.577) foram examinadas 281 pessoas, utilizando os índices preconizados pela OMS (WHO, 1997), CPO-D e ceod, no ano de 2015. Os resultados obtidos no levantamento epidemiológico demonstram que o índice de cárie (CPO-D e/ou ceo-d, de acordo com a faixa etária) foi de 20,27 (5 anos), 4,71 (12 anos), 7,51 (15 - 19 anos), 25,3 (35 - 44 anos ) e 30,4 (65 - 74 anos). Na análise de cada um dos componentes do índice CPOD, observa-se que o componente cariado teve maior relevância nas idades de 12 e 15 - 19 anos. Já nas faixas etárias adulta (35 - 44) e idosa (65 - 74), o componente que mais contribuiu com o alto valor do índice foi o componente "perdido". O índice de cárie dentária apresentou-se elevado, em todas as faixas etárias analisadas, sugerindo que a assistência à saúde bucal e as medidas preventivas básicas dessa comunidade apresentam-se insuficientes para o perfil epidemiológico da população. 
Palavras-chave: Cárie dentária. Epidemiologia. Higiene bucal.

\begin{abstract}
In Brazil, data from the SB Brasil reveal higher levels of caries in the North region and lower levels in the Southeast and South regions. prevention and promotion and rehabilitation in oral health. The aim of this quantitative cross-sectional study was to identify the epidemiological profile of dental caries in residents of the riverside community São José - Vila Arara - Municipality of Caapiranga - Amazonas (AM). To assess the dental condition, after approval by the Ethics and Research Committee of the University Center of Anápolis - UniEVANGÉLICA (opinion 1,053,577), 281 people were examined, using the indices recommended by the WHO (WHO, 1997), CPO-D and ceo- d, in the year 2015. The results obtained in the epidemiological survey show that the caries index (CPO-D and ceo- d, according to age group) was 20.27 (5 years), 4.71 (12 years), 7.51 (15 - 19 years), 25.3 (35 - 44 years) and 30.4 (65 - 74 years). In the analysis of each of the CPOD index components, it is observed that the decayed component was more relevant at ages 12 and 15 - 19 years. In the adult (35 - 44) and elderly (65-74) age groups, the component that most contributed to the high value of the index was the "lost" component. The dental caries index was high in all age groups analyzed, suggesting that oral health care and basic preventive measures in this community are insufficient for the epidemiological profile of the population
\end{abstract}

Key words: Dental cavity, Epidemiology, Oral hygiene.

\title{
1 INTRODUÇÃO
}

No Brasil, a distribuição de cárie apresenta-se de forma desigual, com maiores níveis no Norte. Em grande parte, essa situação é devida às dificuldades sociais e geográficas da região (ARANHA et al, 2020).

O Amazonas é o maior estado brasileiro em extensão territorial possuindo 1.559.148,889 quilômetros quadrados e é composto por sessenta e dois municípios, divididos por grandes massas de água ( BRASIL, 2020).

A maior parte de seu território é coberto pela floresta amazônica e entrecortado pelos rios, paranás, lagos e igarapés, que formam a extensa bacia hidrográfica amazônica - a maior do mundo em volume de água (PONTES, 2009). A população do Estado, de acordo com o Censo 2010, é de 3.483.985 habitantes; a estimativa para 2020 é de e é estimada em 4.207.714 em 2020 (BRASIL, 2020).

Levando em consideração a condição bucal dos moradores ribeirinhos, além das dificuldades físicas impostas pela geografia do norte brasileiro, os próprios moradores relataram conviver constantemente com saúde bucal precária, especialmente dor e perda dentária prematura.

A dor é um sinal que causa desordem, mas que ao mesmo tempo suscita uma organização social para enfrentá-la seja utilizando conhecimentos de ordem científica ou de maneira empírica através, por exemplo, de automedicação e condutas sem comprovação científica, como por exemplo, a aplicação de curativos usando raízes, seiva de plantas ou até mesmo esfregando substâncias que, de acordo com a crença popular, teria ação no dente dolorido (FERREIRA et al, 2006). 
As dificuldades para prestação do serviço em saúde bucal são muitas: a locomoção das equipes de saúde é demorada e trabalhosa; devido à demanda acumulada, é difícil obter vagas e horários para atendimento; é comum a escassez de insumos e materiais; quase sempre não há atendimento com especialistas, em endodontia por exemplo, o que leva à altos números de extração emergencial (PINHEIRO et al, 2002). Como agravantes, tem-se pouco conhecimento em higiene bucal, pouco acesso à produtos de cuidado bucal aliados à escovação e alimentação inadequados.

Diante de tantos desafios, é necessário identificar o perfil epidemiológico e necessidades da população ribeirinha, afinal o planejamento é indispensável para intervir na realidade de forma lógica e ampla. É necessário compreender o que de fato mais atinge as pessoas, levando em consideração distância, mão de obra, custos, tempo de modo que causa, efeito, e intervenções possam oferecer prevenção, promoção, tratamento e reabilitação (PONTE et al, 2019).

Sendo assim para efetivar uma estratégia de ação de combate, faz-se necessário um estudo sistemático do perfil epidemiológico da cárie nessa população ribeirinha: os hábitos e costumes, saneamento ambiental, tratamento de água e higiene bucal. Essas informações permitem entender a dinâmica antropológica e de saúde, especialmente quais as necessidades de tratamento odontológico (CARVALHO; SANTOS; CAMPOS, 2013).

O presente estudo tem como objetivo, identificar o perfil epidemiológico da cárie dentária em moradores da comunidade ribeirinha São José - Vila Arara - Município de Caapiranga - AM baseado em dados de CPO-D e ceo-d.

\section{MATERIAIS E MÉTODOS}

Foi realizada uma pesquisa de campo, usando um estudo transversal com delineamento quantitativo, sob número de registro de Comitê de Ética da UniEVANGÉLICA número 1.503.577. A pesquisa foi realizada na comunidade São José - Vila Arara - município de Caapiranga - estado do Amazonas (AM). Em função da necessidade de se fazer um diagnóstico da saúde bucal da população da comunidade propôsse a realização de um censo. Agentes comunitárias de saúde local relataram um total de 188 famílias locais. Segundo dados do censo do Instituto Brasileiro de Geografia e Estatística de 2010 (BRASIL, 2020), o estado do Amazonas tem número médio de 3,5 pessoas por família totalizando aproximadamente 658 pessoas a serem examinadas.

Para avaliação e levantamento da condição dentária, foram utilizados os índice preconizado pela Organização Mundial da Saúde na quarta edição do manual de saúde bucal CPO-D para dentes permanentes e ceo-d para dentes decíduos (WHO, 1997).

Uma equipe de campo de 8 (oito) acadêmicos passou previamente por treinamento e calibração: foram realizadas oficinas com duração de 12 horas, com objetivo de discutir a operacionalização das etapas 
do trabalho, as atribuições de cada participante e assegurar uniformidade nos procedimentos e metodologia de trabalho. Os integrantes foram então elencados entre examinadores e anotadores. Então, o grupo dividiuse nos 188 domicílios da comunidade para avaliar e coletar os dados sobre saúde bucal populacional, indispensavelmente supervisionados por um professor cirurgião-dentista do Centro Universitário de Anápolis (UniEVANGÉLICA). A coleta de dados ocorreu nos domicílios das famílias e os dados foram tabulados em planilha eletrônica Microsoft Excel para análise.

Cada examinador trabalhou durante 4 horas realizando um número diário máximo de 30 exames. Obteve-se dados sobre cárie dentária, edentulismo, condição socioeconômica, acesso e utilização de serviços odontológicos e autopercepção de saúde bucal. Com tais dados, buscou-se estabelecer uma provável correlação entre os aspectos acima, uma vez que estudos indicam associação entre renda, qualidade de vida, acesso à serviços de saúde e presença de cárie (BRASIL, 2014).

A interpretação, levantamento e escolha dos índices utilizados neste estudo seguiu as metodologia utilizadas para o SBBrasil 2010 que por sua vez seguiu recomendações da OMS na $4^{\text {a }}$ edição de seu Manual de Instruções para Levantamento Epidemiológico Básico em Saúde Bucal (WHO, 1997).

O levantamento epidemiológico foi realizado nos dias 9 e 16 de maio de 2015 e teve como critérios de inclusão: ser morador da comunidade, estar no domicílio no momento da visita dos examinadores, assinatura do Termo de Consentimento Livre e Esclarecido (TCLE) para os maiores de 18 anos e para a população menor de 18 anos o responsável legal deve consentir assinando o TCLE e o menor deve assinar o Termo de Assentimento do Menor. Foram excluídos da pesquisa todos os moradores que não aceitarem participar ou que não se enquadraram em quaisquer critérios de inclusão.

Os dados obtidos foram analisados por meio da estatística descritiva e inferencial, estabelecendo médias e frequências para os índices levantados. Para tratamento estatístico dos dados foi utilizado o programa estatístico IBM-Statistical Package for the Social Sciences (SPSS) 21.0.

\section{RESULTADOS}

Os resultados obtidos no levantamento epidemiológico demonstram que o índice de cárie (CPO-D e/ou ceo-d, de acordo com a faixa etária) foi de 20,27 (5 anos); 4,71 (12 anos); 7,51 (15 - 19 anos); 25,3 (35 - 44 anos ) e 30,4 (65 - 74 anos) conforme apresenta a figura 1. 
Figura 1 - Gráfico indicando os componentes ceo-d e CPO-D de cada faixa etária.

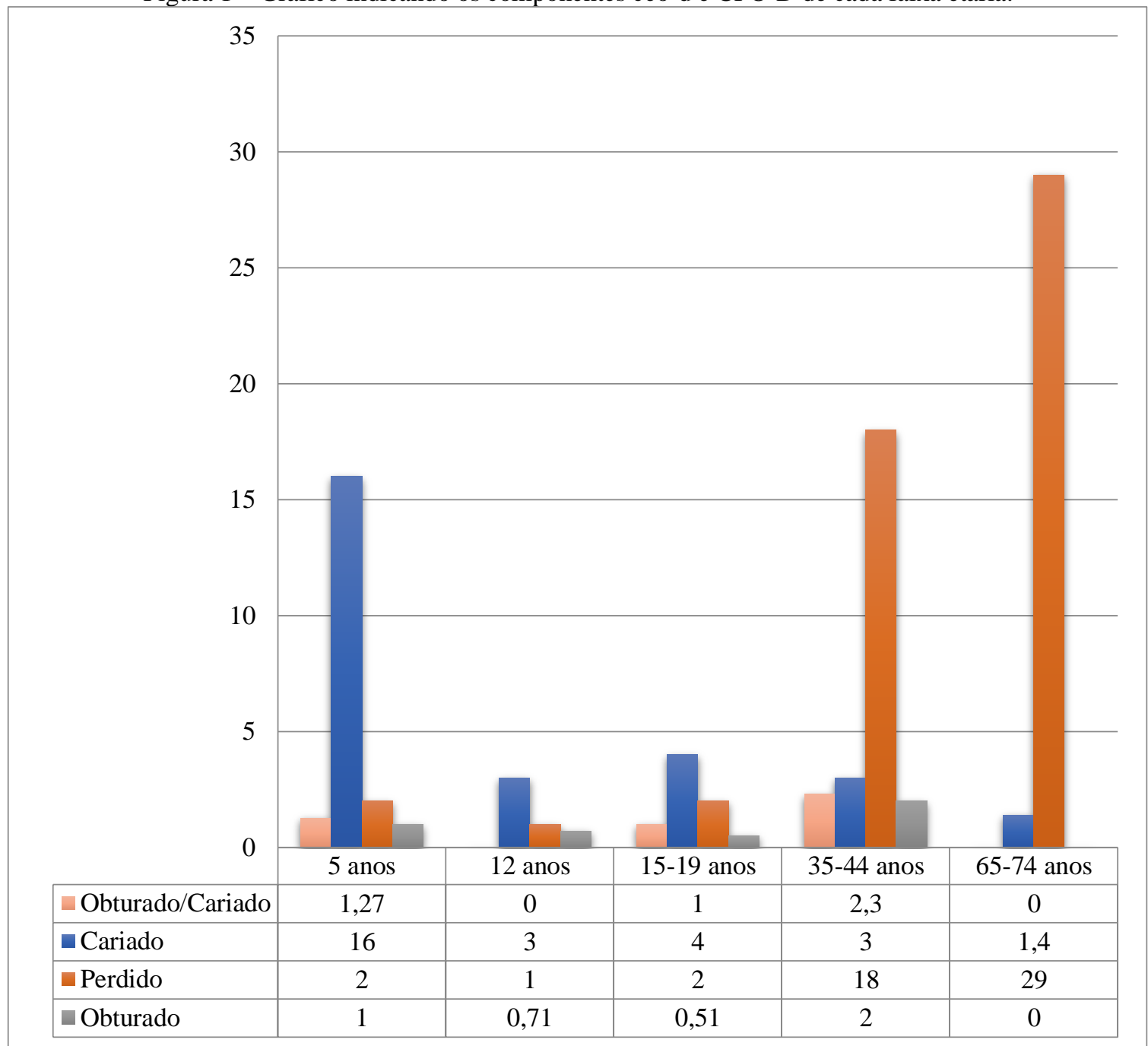

Fonte: os autores, 2021.

$\mathrm{Na}$ análise de cada um dos componentes do índice CPO-D, observa-se que o componente cariado teve maior relevância nas faixas etárias de 12 e 15-19 anos. Já entre adultos (35-44) e idosos (65-74), "perdido" teve maior relevância. O indíce de cárie na idade de 12 anos apresentou-se muito alto em relação à média do Brasil e da região Norte de acordo com o apresentado na figura 2. 
Figura 2 - Gráfico de comparação CPO-D/CEO-d entre Brasil, região norte e comunidade São José do Arara.

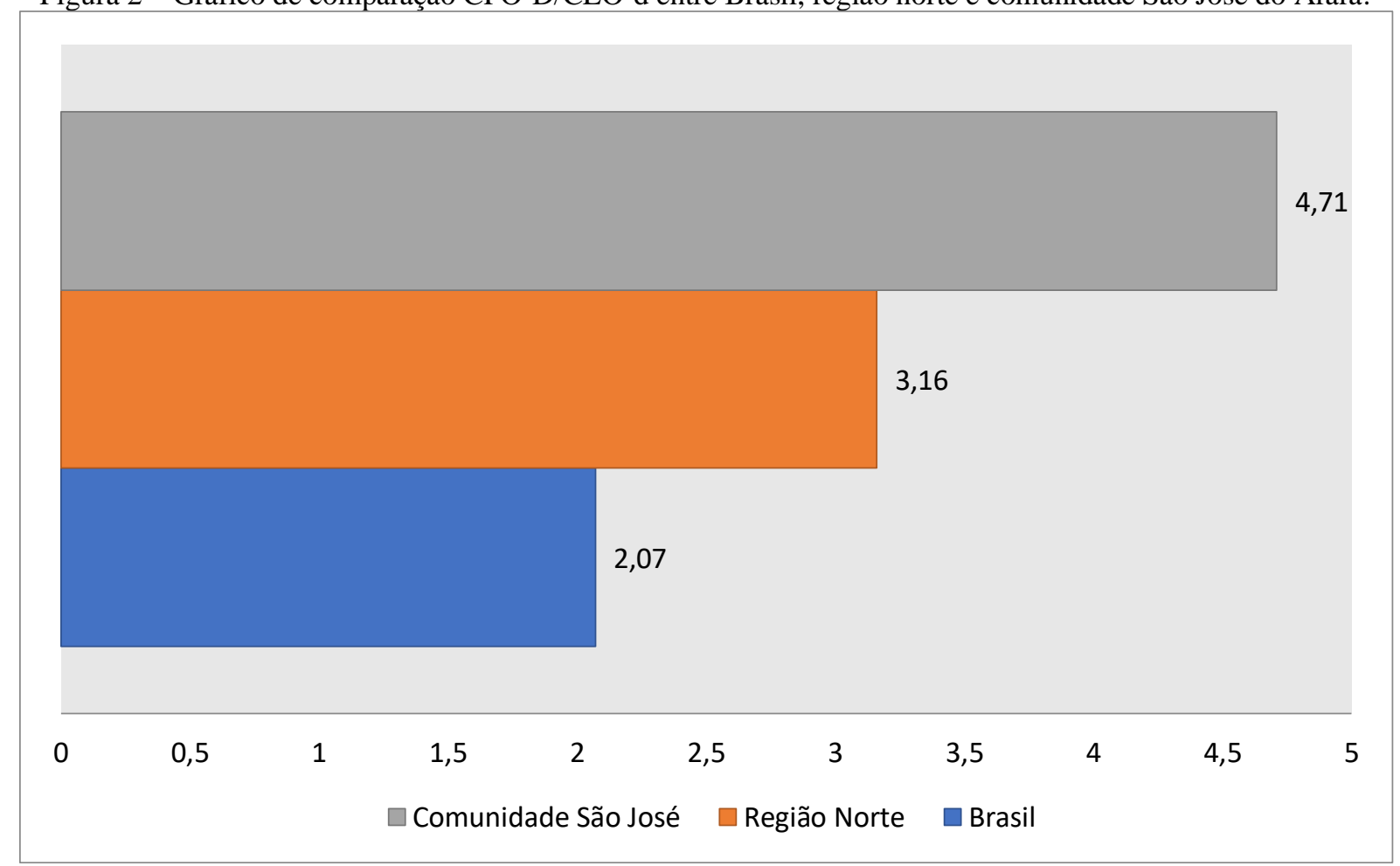

Fonte: os autores, 2021.

\section{DISCUSSÃO}

As comunidades ribeirinhas do interior do Amazonas estão há enormes distâncias dos municípios e principalmente da capital; que não são contadas em quilômetros ou milhas, mas em dias e semanas de viagem de barco. Avaliação dejovens de 12 anos de Manaus encontrou índice cariado de 1,82 na amostra. Maiores médias se deram em grupos com menor renda familiar, de modo que a distribuição desigual de renda reforça ainda mais a falta de acesso à prevenção bucal (DA SILVA, et al, 2008).

Estudo em uma população ribeirinha do estado de Rondônia, pertencente à região norte do Brasil, identificou que o componente cariado é aquele que possui maior relevância, alcançando níveis de 4,30 (DA SILVA et al, 2008). Contudo, a média para o componente cariado obtido neste trabalho, após análise matemática em software específico, foi de 20,27 nos "cariados". Fatores como a falta de acesso aos cuidados em saúde bucal, aliada ao consumo de água não fluoretada e a precária educação em saúde bucal são determinantes para precária saúde bucal (CYPRIANO, et al, 2003).

Segundo o levantamento SB Brasil 2010, o CPO-D na faixa etária de 15 a 19 anos, na média geral brasileira, está em 4,25, acima da média para a região Norte que é de 3,16. Neste estudo, obteve-se 7,51, mais alto que o restante da região Norte, e muito superior a 1,72 de CPO-D para a faixa etária na região Sudeste, que tem menor índice do país. Carneiro e colaboradores (2008) analisaram o CPO-D em índios Baniwa e encontraram um dado ainda mais grave: 8,2 como resultado. Afirmam que a alimentação dos indígenas é baseada em mandioca, frutas, peixes e carnes de caça, porém, é comum a troca desses alimentos, 
por industrializados, ou seja, mesmo com a preservação da essência da alimentação dentro dos parâmetros indígenas, é bastante comum o consumo de açúcares em várias apresentações, o que explica o alto índice de "cariados", aliado à pouca instrução acerca de higienização e prevenção (CARVALHO; PASSOS; AMARAL, 2014).

O estudo do Ministério da Saúde, SB Brasil 2010, ressalta que entre 35 e 44 anos, os dentes cariados são poucos em face dos perdidos e obturados, que tem níveis praticamente iguais de representatividade, enquanto que os acometidos por cárie são correspondentes a uma pequena parte dos dados. O CPO-D da média brasileira para esta faixa etária é de 16,75. Nesse trabalho na comunidade de São José do Araras, encontrou-se níveis de 25,3, o que representa bem acima da média nacional. Cite-se, ainda, que essa disparidade entre a amostra e a média brasileira se deve principalmente pelo alto número de perdidos em São José, que é responsável por aproximadamente $70 \%$ dos casos, e o restante é divido entre obturado e cariado, com pouca representatividade para meios de comparação.

Na observação de 65 a 74 anos, aqui obteve-se valor de 30,4, sustentado principalmente pelo componente perdido, e uma pequena expressão de cariado. Não há dados de obturados. Mais uma vez, a média brasileira desta faixa, está abaixo aos obtidos, girando em torno de 27,53.

Dados do SBBrasil 2010, sustentam que a média encontrada de CPO-D no Brasil é de 2,07, e uma análise rápida dos resultados por região deixa claro que em regiões como Sul e Sudeste, a saúde bucal da população é superior àquela das regiões como Norte e Nordeste, indo de encontro com argumentos de vários autores que reforçam falta de investimento em políticas de saúde eficiente, fluoretação da água de abastecimento público, atendimento odontológico preventivo e informação em escovação dental adequada. A comunidade aqui analisada obteve CPO-D acima até da média do estado do Amazonas que é de 3,16, enquanto na população ribeirinha, chega a 4,71 .

A análise da prevalência de cárie em duas comunidades ribeirinhas do estado do Pará indicou que fatores como a desigualdade social manifestam-se em maior número de dentes cariados em comparação com o restante do Brasil; por conseguinte, a saúde bucal dos moradores requer maiores tratamentos e ações de prevenção mais intensivas. Áreas carentes como vilas e cidades com menor renda têm maiores índices de cárie, o que está diretamente relacionado ao encurtamento da renda familiar, e Índice de Desenvolvimento Humano (IDH) mais baixo (BRASIL, 2010). Neste estudo, a realidade encontrada é condizente com o relatado na literatura; sendo evidente que prevenção e tratamento odontológicos são extremamente deficitários: todas as idade têm problemas de saúde bucal, desde acúmulo de placa bacteriana, passando por números alarmantes de cárie dental, até necessidade de próteses, sejam elas parciais ou totais.

Mesmo que saúde seja um direito assegurado pela Constituição Federal brasileira em ser artigo 196 (BRASIL, 1988), mesmo com a gratuidade, o acesso ainda não é garantido à qualquer cidadão em qualquer 
localidade, principalmente pela falta de meios físicos, materiais, mão de obra, que sejam capazes de atender a região ribeirinha do Amazonas ${ }^{20}$. Pois bem, em São José verificou-se a o funcionamento de Unidade de Saúde da Família com todo o aporte básico para tratamento médico e odontológico, porém, o cirurgião dentista visita a comunidade uma semana por mês e é funcionário do município de Caapiranga. Fato facilmente notado é que apenas essas visitas programadas não estão sendo suficientes para sanar ou pelo menos controlar as doenças bucais da comunidade ribeirinha. Principalmente as crianças têm sofrido muito com dores e perda precoce de elementos dentários. Geralmente os responsáveis, ao serem indagados sobre o porquê de tal situação, respondem enfaticamente com "é de leite esse dente, logo vai trocar", o que é claramente indicativo de não instrução sobre a importância da dentição decídua para a infância e o restante da vida.

Cazotti et al, (2012) explicam em seu trabalho, que as condições de saúde bucal da população, tão afetada por cárie dentária, se dá pela falta de cuidado em odontologia preventiva, inexistência de água fluoretada para consumo populacional e alimentação com potencial cariogênico em uso durante várias vezes ao dia. Na comunidade de São José encontrou-se uma realidade que se equipara e reforça o que dizem os autores, pois há alto consumo de refrigerante de marca conhecida na região Norte, salgadinhos de milho estão amplamente presentes em para qualquer idade e muitos doces ditos como infantis sendo balas e chicletes, que são utilizados sem nenhum controle, tampouco preocupação com higienização. Esperava-se alto nível de cárie dentária, o que foi confirmado pela coleta de dados baseada na avaliação intra-oral, resultando em níveis muito mais altos que a média da região Norte, bem como ainda mais acima da média nacional, como afirma o SB Brasil de 2010.

\section{CONCLUSÕES}

Conclui - se que :

- O índice de cárie dentária apresentou-se elevado em todas as faixas etárias analisadas;

- A assistência à saúde bucal e as medidas preventivas básicas dessa comunidade apresentam-se desorganizadas e negligenciadas pelas autoridades, necessitando de uma atenção maior por parte do governo e do Cirurgião-Dentista.

A participação dos cirurgiões-dentistas no Projeto Amazonas permitiu observar que a população assistida representa apenas uma parcela de toda população existente na região amazônica e tratamentos odontológicos devem ser realizados para devolver a qualidade de vida para essas pessoas, que ainda apresenta-se em alta precariedade. Esses dados devem chamar atenção da população brasileira e dos governantes para que medidas sejam tomadas, afim de que haja a congruência da exuberância de um cenário natural com a saúde da população que habita a região. 


\section{APLICAÇÃO CLÍNICA:}

A análise minuciosa e ampla do perfil epidemiológico em saúde bucal da população que fora objeto deste estudo, pode e poderá servir como base para criação e moldagem de políticas de saúde e estratégias de execução de serviços de assistência odontológica, levando em consideração as necessidades da população e de cada faixa etária, de modo que, especificamente, hajam ações voltadas à prevenção, promoção e reabilitação da saúde oral dos ribeirinhos.

\section{AGRADECIMENTOS}

Nosso sincero e cordial agradecimento àqueles que nos prestaram apoio e nos auxiliaram na escrita deste: Prof. Julianna Amaral Cavalcante, Prof. Pedro Paulo Ferreira Espíndola, Prof. Fábio, Prof. Regina Mota Carvalho, Asas de Socorro. 


\section{REFERÊNCIAS}

ARANHA, L. A. R.; LIMA, R. V.; MAGALHÃES, W. O. G.; MORAES, F. H.; ARANHA, G. A.; REGIS, R. A. Associação entre excesso de peso corporal e experiência de cárie dentária em estudantes do município de Barcelos, Amazonas, Brasil: um estudo transversal. Arq Odontol, Belo Horizonte, v. 36, n. 11, p. 1-10. Disponivel em: https://periodicos.ufmg.br/index.php/arquivosemodontologia/article/view/15902. Acesso em: 11 set. 2021.

BRASIL-IBGE Notícias. 2020. Brasília, DF: Instituto Brasileiro de Geografia e Estatística, DF: c2020. Disponivel em: https://agenciadenoticias.ibge.gov.br/agencia-sala-de-imprensa/2013-agencia-denoticias/releases/27737-ibge-atualiza-dados-geograficos-de-estados-e-municipiosbrasileiros\#: :text=O\%20maior\%20dos\%20estados\%20continua, \%C3\%A1rea\%20de\%205.760\%2C783 $\% 20 \mathrm{~km} \% \mathrm{C2} \%$ B2. Acesso em: 29 set. 2020

BRASIL - IBGE . 2010. Instituto Brasileiro de Geografia e Estatística: Censo.Amostra - Famílias. Brasília, DF: IBGE, c2010. Disponível em: https://cidades.ibge.gov.br/brasil/am/pesquisa/23/24161?detalhes=true. Acesso em 10 jun. 2021.

BRASIL - IBGE. 2020. Brasília - DF: Instituto Brasileiro de Geografia e estatística. Brasília, DF: c2020. Disponivel em: https://cidades.ibge.gov.br/brasil/am/panorama. Acesso em 28 ago. 2020.

BRASIL - SBBRASIL 2010: pesquisa Nacional de Saúde Bucal: resultados principais. Brasília - DF: Ministério da Saúde: Secretaria de Atenção à Saúde: Secretaria de Vigilância em Saúde. c, 2014. Disponível em: https://bvsms.saude.gov.br/bvs/publicacoes/pesquisa_nacional_saude_bucal.pdf. Acesso em 10 set. 2021.

BRASIL. [Constituição (1988)]. Constituição da República Federativa do Brasil. Brasília, DF: Senado Federal, 2016. 496 p. Disponível em: https:/www2.senado.leg.br/bdsf/bitstream/handle/ id/518231/CF88_Livro_EC91_2016.pdf. Acesso em: 9 mai. 2021.

CARNEIRO, M. C. G.; SANTOS, R. V.; GARNELO, L.; REBELO, M. A. B.; JUNIOR, C. E. A. C. Cárie dentária e necessidade de tratamento odontológico entre os índios Baniwa do Alto Rio Negro, Amazonas. Ciência \& Saúde Coletiva, v. 13, n. 6, p. 1985-1992, 2008. Disponível em: https://www.scielo.br/j/csc/a/76mnch6DkwsPGfthwhWzySG/?format=pdf\&lang=pt. Acesso em 11 set. 2021.

CARVAlHO, D. A.; PASSOS, G. L. S.; AMARAL, R. C. Prevalência de cárie e necessidades de tratamento em duas comunidades ribeirinhas - Pará, Brasil. J Health Sci Inst, v. 32, n. 1, p. 23-27, 2014. Disponível em: https://repositorio.unip.br/wp-content/uploads/tainacanitems/34088/34977/V32_n1_2014_p23a27.pdf. Acesso em 10 jan. 2020.

CARVALHO, M.; SANTOS, N. R.; CAMPOS, G. W. S. A construção do SUS e o planejamento da força de trabalho em saúde no Brasil: breve trajetória histórica. Saúde em Debate, v. 37, n. 98, p. 372-387, 2013. Disponivel em: https://www.scielosp.org/pdf/sdeb/2013.v37n98/372-387/pt. Acesso em 06 jul. 2021.

CYPRIANO, S. PECHARKI, G. D.; SOUSA, M. L. R.; WADA, R. S. A saúde bucal de escolares residentes em locais com ou sem fluoretação nas águas de abastecimento público na região de Sorocaba, São Paulo, Brasil. Cadernos de Saúde Pública, v. 19, n. 4, p. 1063-1071, 2003. Disponível em: https://www.scielo.br/j/csp/a/ZLJ4kGnWP9wYMNvCnN8MLLH/?format=pdf\&lang=pt. Acesso em 27 janeiro 2021. 
DA SILVA, R. H. A.; CASTRO, R. F. M.; CUNHA, D. C. S.; ALMEIDA, C. T.; BASTOS, J. R. M.; CAMARGO, L. M. A. Cárie dentária em população ribeirinha do Estado de Rondônia, Região Amazônica, Brasil, 2005/2006. Cadernos de Saúde Pública, v. 24, n. 10, p. 2347-2353, 2008. Disponível em: https://www.scielo.br/j/csp/a/CVFNW8jMyDxrMmq9kSkFVtr/?format=pdf\&lang=pt. Acesso em 09 set. 2021.

FERREIRA, A. A. A.; PIUVEZAM, G.; WERNER, C. W. A.; ALVES, M. S. C. F. A dor e a perda dentária: representações sociais do cuidado à saúde bucal. Ciência \& Saúde Coletiva, v. 11, n. 1, p. 211-218, 2006.

PINHEIRO, R. S.; VIACAVA, F.; TRAVASSOS, C.; BRITO, A. S. Gênero, morbidade, acesso e utilização de serviços de saúde no Brasil. Ciência \& Saúde Coletiva, v. 7, n. 4, p. 687-707, 2002.

PONTE, Y. O.; GIRÃO, D. C.; VASCONCELOS, A. A.; CARNEIRO, S. V.; PINTO, M. R. Planejamento estratégico em saúde pública com foco na saúde bucal: uma revisão de literatura. Revista Expressão Católica Saúde, v. $\quad 4, \quad$ n. $\quad 2, \quad$ p. $\quad 35, \quad 2019 . \quad$ Disponível em: http://publicacoesacademicas.unicatolicaquixada.edu.br/index.php/recsaude/article/view/3257/PLANEJA MENTO\%20ESTRAT\%C3\%89GICO. Acesso em 06 set. 2021.

PONTES, F. C. C. Condição de Saúde Bucal em Populações Ribeirinhas no Estado do Amazonas: estudo de caso. 2009. 127 f. Tese (Doutorado em Ciências de Saúde Pública). Fundação Oswaldo Cruz, Rio de Janeiro, 2009. Disponível em: https://bvssp.icict.fiocruz.br/pdf/CohenCarneirofd.pdf. Acesso em 07 set. 2021.

WHO, World Health Organization. Oral Health Survey. Geneva: WHO, 1997, 79 p. 